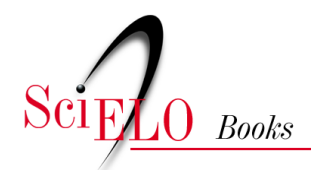

\title{
ed
}

\section{Apresentação e agradecimentos}

\author{
Fabiano Santos
}

\section{SciELO Books / SciELO Livros / SciELO Libros}

SANTOS, F. Apresentação e agradecimentos. In.: SANTOS, F., ed. Congresso remoto: a experiência legislativa brasileira em tempos de pandemia [online]. Rio de Janeiro, 2021, pp. 9-11. Sociedade e política collection. ISBN: 978-65-8880812-2. https://doi.org/10.7476/9786588808122.0001.

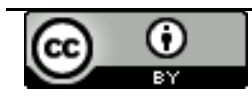

All the contents of this work, except where otherwise noted, is licensed under a Creative Commons Attribution 4.0 International license.

Todo o conteúdo deste trabalho, exceto quando houver ressalva, é publicado sob a licença Creative Commons Atribição 4.0.

Todo el contenido de esta obra, excepto donde se indique lo contrario, está bajo licencia de la licencia Creative Commons Reconocimento 4.0. 


\section{Apresentação e Agradecimentos}

O ano de 2020 trouxe à sociedade brasileira uma enorme cota de sacrifício. Como se não bastasse a continuidade de um cenário econômico desfavorável, o país é atingido de maneira contundente e dramática pela crise de saúde decorrente da Covid-19. A todas e todos é imposta uma situação de isolamento, para alguns implicando a adaptação de atividades, antes e sempre presenciais, para o contexto remoto, para muitos, entretanto, a pura e simples paralisação de qualquer atividade remuneratória e profissional. No meio de tantas dificuldades e novidades impensáveis, o Congresso Nacional decide manter seu funcionamento e assumir o protagonismo político no enfrentamento do problema sanitário, uma vez que o presidente Jair Bolsonaro se recusava a conceder relevância ao que para a grande maioria do mundo político parecia uma obviedade. Estabelece assim o Sistema de Deliberação Remota (SDR), sistema pelo qual, por meio de mudanças regimentais, o Legislativo passou a funcionar de maneira não presencial.

De imediato, organizações da sociedade civil, voltadas para o acompanhamento do Congresso Nacional, demonstraram preocupação com as possíveis consequências, sociais, econômicas e políticas da adoção do SDR. Várias delas não apenas se preocuparam com o cenário, mas também buscaram parcerias tendo em vista analisar e entender a nova forma de procedimento legislativo. Este volume nasce assim de um chamamento feito pela Rede de Advocacy Colaborativo (RAC) ao Observatório do Legislativo Brasileiro (OLB) ${ }^{1}$,

1 A equipe do OLB agradece pelo apoio recebido desde sua origem da Open Society Foundation e do Instituto Clima e Sociedade. 
um laboratório acadêmico do Instituto de Estudos Sociais e Políticos da Universidade do Estado do Rio de Janeiro (IESP-UERJ), apoiado pelo Instituto da Democracia e da Democratização da Comunicação (INCT), para se unir, junto à Dado Capital e à Pulso Público, ao esforço de gerar informação de qualidade sobre o Legislativo em tempos de pandemia. $\mathrm{O}$ entrosamento e engajamento das equipes foram empolgantes a ponto de sugerir a organização de um produto que tornasse permanente a experiência cotidiana de acompanhar o Congresso em cenário tão desconcertante.

Todos os capítulos do volume, com exceção do primeiro e do sétimo e das notas conclusivas, foram produzidos no contexto do projeto "Congresso Remoto", iniciativa da RAC, apoiada pela Fundação Laudes e Fundação Avina, projeto em parceria da Dado Capital e Pulso Público com o OLB. Agradeço às pessoas que fizeram parte do projeto, tornando possível a disponibilização para o público brasileiro das várias dimensões envolvidas nessa experiência tão fascinante de adoção pelas duas Casas do Congresso do sistema virtual de funcionamento. Em especial, pela RAC e Fundação Avina, agradeço à Glaucia Barros. Pela Dado Capital, Saulo Porto e Nazareno Andrade. Pela Pulso Público, Vitor Oliveira, Andresa Porto e Pedro Gomes. Pelo OLB, André Félix e André Madruga. No Legislativo brasileiro, a Patrícia Gomes Rego de Almeida, Marcus Vinícius Chevitarese Alves, Cristiano Ferri Soares Faria e ao deputado Marcelo Calero. Especial menção deve ser feita a José Szwako, editor da coleção "Sociedade e Política, uma joint venture" da EdUERJ com o IESP-UERJ e a Cristina Buarque, colega no Instituto, responsáveis pelo ágil parecer acadêmico em apoio à publicação do volume. Finalmente, é importante mencionar que o capítulo 1 é versão modificada de artigo publicado no primeiro número da E-Legis, uma revista Eletrônica da Câmara dos Deputados do Brasil, deste ano de 2021, um dossiê intitulado "Ações Legislativas e enfrentamento à pandemia da Covid-19”. Grato às editoras do dossiê, Fátima Anastasia, Gelga 
Almeida e Luciana Santana e a Antonio Teixeira Barros, editor da revista, pela permissão de publicar uma nova versão do artigo neste volume.

Responsabilidade pelos erros e omissões, é claro, cabe unicamente ao organizador, autoras e autores dos capítulos.

Fabiano Santos 